\title{
"You Understand, But You Don't Believe It": Tracing the Stabilities and Instabilities of Interaction in a Physics Classroom Through a Multidimensional Framework
}

\author{
Kevin M. Leander and David E. Brown \\ Department of Curriculum and Instruction \\ University of Illinois, Champaign-Urbana
}

\begin{abstract}
This article develops a multidimensional framework for analyzing an extended classroom interaction in an effort to understand the resources participants draw on, the alignments they form, and the meanings and context they construct. The framework is comprised of six different dynamics identified in the interaction: focal, conceptual, institutional, discursive-symbolic, social, and affective. These dynamics, which we term (in)stabilities, provide a way of understanding the complex coordination of relatively stable aspects of the interaction by participants as well as the highly unstable negotiations of meaning. Interrelated with the construction of context, we consider how participants negotiate their positions, focusing especially on one resistant student. By considering the extended interventions made on her behalf, we address why it is that she remains unconvinced of others' arguments and evidence. In conclusion, we consider the implications of the (in)stabilities framework, as well as of this particular classroom interaction, for research and instruction.
\end{abstract}

When analyzing a discussion or group interaction in science, researchers often privilege a particular perspective, typically making reference to other relevant perspectives that could be considered in a different type of analysis. In these cases, researchers focus on particular aspect(s) of the interaction, considering these as "signal" and considering other aspects as "noise" that is ignored as irrelevant to the

Requests for reprints should be sent to Kevin M. Leander, University of Illinois, 311 Educational Building, 1310 S. Sixth Street, Champaign, IL 61820-6990. 
purposes of analysis. For instance, work that focuses on cognition will typically gesture toward social aspects of interaction but not include these aspects in the analysis. Conversely, work that focuses on aspects of social interaction will often avoid, explicitly or implicitly, perspectives on the interaction that posit internal states of the interactants. Both cognitive and social analyses often avoid addressing affective issues or issues of the larger institutional context.

In this article, we explored an alternate approach. Rather than choosing a priori to focus on particular aspects of the interaction, we wanted as much as possible to treat everything as signal. This is, of course, impossible with a data source as rich as a 15-min videotape of a complex classroom interaction. By holding this as a goal, however, we were able to "broaden the blinders" at least somewhat in order to consider aspects of the interaction that are rarely considered together. Out of this interpretive analysis emerged a multilayered framework that attempts to relate several aspects of the interaction.

Although we try not to privilege a particular theoretical orientation, we found that the orientations we drew on did share some overall characteristics, in particular notions of stability, instability, and dynamic interaction. Through analyzing a rich transcript of classroom interaction at length, we attempted to tease out the dynamics that have seemed most salient and meaningful. We identified these dynamics as various "(in)stabilities" because each is characterized by movement and negotiation on one hand and fixation or alignment on the other hand. The metaphor of the dance captures something of the coordinated and contrary movements; hence, we consider the entire discussion analyzed as a "dance of (in)stabilities." Through this analysis, we focus on three central questions. First, what do the multiple (in)stabilities and their interactions suggest about this particular classroom context and its construction? How might this relate to other science classroom interactions? Second, what are the positions that individual students take up through these multiple (in)stabilities? How do they negotiate these positions? Third, in a highly interactive context largely directed toward convincing one resistant student of a scientific answer to a problem, why is it that she remains unconvinced? Why is there so little conceptual movement on her part, in a classroom environment so rich in student-student interactions, multiple representations of the same problem, connections to real-world experience, and other aspects of the discussion that may be considered to be positive classroom experiences?

\section{THEORETICAL BACKGROUND}

Theorists from widely diverse traditions have considered stability and instability from, among others, conceptual, discursive, historical, and sociological perspectives. These multidisciplinary perspectives, and the generative interplay among them, provide theoretically rich groundwork for understanding (in)stabilities 
within classroom interactions. In the following sections, we briefly review three scholarly traditions that have informed our analysis: First, we consider work in conceptual change; second, we focus on discursive interactions; and third, we consider (in)stability across entire systems of activity. Our purpose is not simply to move stepwise through these increasingly broad dynamics, replacing one dynamic with another, but rather to begin to suggest relations among their various (in)stabilities.

\section{Conceptual Stability and Instability}

One of the most salient aspects of the interchange we focus on here is the counterintuitive problem context the teacher poses and the students experience. In the interchange, various individuals exhibit intrapersonal conceptual stability and instability, and various pairs or groups exhibit conceptual alignments and misalignments at the interpersonal level. In the following discussion, we focus on conceptual stability and instability at both the intrapersonal and interpersonal levels.

Historically, virtually all scientists and philosophers assumed until relatively recently that the basic worldview of all but insane individuals is essentially the same. When Piaget first observed nonconservation among the children he was studying, he attributed this behavior indicating a bizarre fundamental worldview to the epilepsy of the children he was studying (Duckworth, 1987). That children might have different views on such fundamental notions as space and quantity was unheard of at the time. Although many of Piaget's specific findings and conclusions have since been challenged, these findings opened the door for others to consider interpersonal conceptual misalignments at deep levels. In recent years, there has been an explosion of research attempting to identify such conceptual misalignments, which are variously called misconceptions, preconceptions, alternative frameworks, children's science, and so forth (for a bibliography including 4,500 references, see Pfundt \& Duit, 1998). In the episode we focus on here, we will see a number of examples of misalignments at a deep conceptual level.

Although few modern researchers question the presence of such misalignments at the interpersonal conceptual level, there is still substantial debate about the stability or instability of these conceptions at an intrapersonal level. Initially, these interpersonal conceptual misalignments were taken as evidence of stable "alternative frameworks" or "naive theories" roughly on a par with the stability of established scientific theories in the minds of the scientifically sophisticated. However, this initial position has been strongly challenged by some who view these interpersonal misalignments as evidence of intrapersonal instability in the form of subliminal knowledge fragments that are assembled and instantiated in a rather ad hoc fashion in particular contexts at particular times (diSessa, 1988; 1993; Yates et al., 1988). Although McCloskey (1983) talked about the "naive impetus theory" as virtually identical in scope and stability to medieval impetus theo- 
ries, diSessa (1988) countered in one of his studies that "literally no one gave and maintained a pure ... impetus explanation" (p. 60). By contrast, Vosniadou and Brewer (1992) presented strong evidence of substantial coherence in the naive astronomical models of elementary children. In the midst of this debate, others attempted some kind of conciliation among the disparate views. Hammer (1996) looked closely at a segment of classroom interaction and discussed how both perspectives of stability and instability are valuable in making sense of the interaction, and Brown $(1993,1995)$ proposed a framework for interpreting students' conceptions that embraces both stability and instability. In the analysis here, we adopt such a multidimensional perspective, viewing interpersonal and intrapersonal conceptual aspects as participating in the dance of stabilities and instabilities. As such we align with the spirit of Piaget's dynamic notion of equilibration, which includes both stability and instability as essential elements:

There is always some production, that is, some kind of transformation taking place. Similarly there is always some conservation, something that remains the same throughout the transformation. These two are absolutely inseparable. Without any transformation we have only static identity. The world becomes rigid and unchanging in the sense that Parmenides (c. 539 B.C.) conceived it. Without any conservation we have only constant transformation. There is total change; the world is always new and it becomes unintelligible. It becomes like the world of Heraclitus with its river in which one was never able to bathe twice. In reality, there are always both conservation and production. (Piaget, 1977, p. 840)

This discussion introduces the notion of a dynamic interplay among relatively stable and unstable aspects of a particular context. Unlike many discussions that find contrasts between conceptual (or cognitive) and discourse (or activity) perspectives, this perspective of a dynamic dance of stabilities and instabilities is quite resonant with discussions in literature focusing on discourse and on activity systems.

\section{Discursive Stability and Instability}

Negotiation and alignment. Many scholars of discourse within and beyond the classroom have emphasized how meanings move between stability and instability as they are socially negotiated (Cazden, 1988; Edwards \& Mercer, 1987; McDermott \& Roth, 1978). Dore and McDermott (1982) posited an "interactional account" to talk, which argues that talk is "fundamentally indeterminate" apart from a contextualized analysis (p. 375). An interactional account seeks to portray how participants organize their talk to accomplish work at a social level and how this work relates to the meanings of the talk. In such an approach, individual behav- 
ior is understood in terms of how it coconstructs meaning with the behaviors of others in the interaction (McDermott \& Roth, 1978). From such perspectives, we can speak of "alignments" between interactants as coordinated movements or occasions of context building in which some degree of stability is reached.

Goffman (1981) greatly enriched our understanding of such alignments among participants and their activities, terming them footings. As participants express and respond to utterances and other forms of activity, they constantly change their "frame" for events, that is, their footing. Footings themselves must be understood across a broad social spectrum of actual and possible interactants. Goffman challenged folk categories of "hearer" and "speaker" within interactional analyses: For example, a hearer might be an individual with a "ratified social place in the talk" (p. 131), a person directly addressed by the speaker but not necessarily so; a hearer may also be an unaddressed bystander, an unaddressed but official overhearer, an eavesdropper, and so forth. Our concern here is not to decompose these various roles but to highlight the complexity of alignments when classroom discourse analysis moves beyond teacher-student dyads and considers the "dynamic system of relationships and structures" at work in classrooms (Gutierrez, Rymes, \& Larson, 1995, p. 446). In sum, students do not simply answer teachers' questions, but in speaking, they position themselves within complex and dynamic social worlds.

Recently, scholars have also analyzed how discourse coherence, particularly as understood by the theme and structure of arguments, might be best understood and analyzed across the entire interaction of a group, networked among diverse temporal sequences, rather than stepwise or through individual contributions (Pontecorvo \& Girardet, 1993: Resnick, Salmon, Zeitz, Wathen \& Holowchak, 1993). Such work on cognitive distribution in discourse suggests the development of relatively stable generic activity concurrent to the unpredictable direction of an unfolding interaction.

In learning science, alignment and negotiation are also useful constructs for thinking about how participants together construct a focal situation for analysis. Focal stabilization can be characterized as a process of objectification, in which aspects of the "external" world are "generated on the basis of firmly shared ecological-cultural background conditions" (Rommetveit, 1992, p. 22). The lack of shared background is explored in this article, as well as how divergent goals thwart the movement toward focal stability. Yet, more than simply fixing or stabilizing an "external reality," focal (in)stabilities are highly interactive with discursive-symbolic (in)stabilities, an argument well developed by Driver, Asoko, Leach, Mortimer, and Scott (1994). Driver et al. argued that students are not simply reading the "book of nature" in scientific study but are struggling to interpret and make meaning of the symbolic constructs that the science community has advanced as interpretations of nature. Students' interactions with symbolic realities are as much, if not more, significant than their interactions with "natural" realities in 
their enculturation into science. Furthermore, where the distance is great between scientific symbolic realities and personal constructions based on social negotiations and observation of the natural world, students are likely to face a great deal of struggle in appropriating scientific concepts. Thus, the struggling student's location in the "gap" between a focal situation and the symbolic or the commonsensical and the scientific, is a highly fluid location for the discussion of (in)stabilities.

Internally persuasive and authoritative discourses. Lemke's study of secondary science discourse analyzes classrooms as sites of discursive contestation, with an emphasis on how secondary science is driven by authority. Lemke discussed how the teacher wields authority over the students through his or her position that is established by the world of science as well as by the microworld of the classroom. The classroom territory Lemke mapped out is one in which the teacher uses alienating scientific and technical language while the students use commonsense language and intuition and are consequently "mystified" by the science. The territory is one in which the teacher demonstrates conclusions in a standard scientific manner while the students are poor imitators of such rational practice. In this article, we extend Lemke's critique of hegemony in schooled science and, in doing so, find the work of the Russian literary critic, philosopher, and linguist Mikhail Bakhtin especially germane.

For understanding the related dynamics of authority, discourse, and making meaning, a central insight from Bakhtin (1981) concerns the dialogicality of discourse. To assert that discourse is dialogic is to claim that engaging in interaction always involves positioning oneself (or one's voice) with respect to others. According to Bakhtin, our speech practices are shaped through constant interaction with others, in which we assimilate, with more or less creativity, others' utterances and voices. An individual's utterances respond to the past utterances of others and also anticipate future utterances, hence reflecting such past and future voices in the chain of communication. Therefore, an individual's discourse is filled with varying degrees of "otherness" and "our-own-ness" (Bakhtin, 1986, p. 90). Viewing language practice in this way implies that understanding itself is a social process of dialogue:

To understand another person's utterance means to orient oneself with respect to it, to find the proper place for it in the corresponding context. For each word of the utterance that we are in process of understanding, we, as it were, lay down a set of our own answering words. The greater their number and weight, the deeper and more substantial our understanding will be. ... Any true understanding is dialogic in nature. (Voloshinov, 1929/1973, p. 102).

Because he considers an individual's voice continually constructed through the interanimation of other voices within interaction, Bakhtin's $(1981,1986)$ linguistics are a potent expression of the instability, or ongoing development of individual 
voices and understandings, as well as of the instability of language itself. At the same time, this instability is always in play with stable language forms - a tension broadly expressed by Bakhtin as the dynamic of centripetal (centralizing) versus centrifugual (decentralizing) forces. Examples of relative stability analyzed by Bakhtin (1986) include speech genres, historically developed word definitions, and of particular interest here, "authoritative discourse." Authoritative discourse comes to us as monologic and relatively static, already imbued with authority that cannot be altered:

It is indissolubly fused with its authority - with political power, an institution, a person-and it stands or falls together with that authority. One cannot divide it up-agree with one part, accept but not completely another part, reject utterly a third part. (Bakhtin, 1981, p. 343)

Other scholarship has made productive use of the dynamics of authoritative and internally persuasive discourses within disciplinary enculturation (Prior, 1995). In the following analysis, we interpret as highly authoritative discourse that which is given by the teacher (primarily) as formal mathematical-symbolic proof, carrying with it the weight of past scientific authorities. An example is the following teacher's equation: "Maximum force happens when the maximum $x$ happens; maximum $x$ happens at A." We have termed this discursive type mathematical-authoritative discourse.

In contrast to authoritative discourse, Bakhtin (1981) poses "internally persuasive" discourse, which is much more an expression of instability, contingency, and development; internally persuasive discourse "is affirmed through assimilation, tightly interwoven with "one's own word"” (p. 345). As it moves from context to context and speaker to speaker, internally persuasive discourse accrues new meanings. Furthermore, internally persuasive discourse is also given to the creation of discursive "hybrids," which are utterances by a single speaker that reflect more than one social language and belief system (Bakhtin, 1981, p. 304). Internally persuasive discourse can be often heard in the students' constructions of evidence, drawing on animated storytelling and commonsensical reasoning. What most interests us in the analysis is the ongoing positioning of authoritative and internally persuasive discourses, the conflicts they create, and their hybridizations.

\section{Stability and Instability Across an Activity System}

One interdisciplinary approach to understanding the relations formed among diverse aspects of activity is through Soviet and other expressions of activity theory (Engestrom, 1993; Leont'ev, 1978; Wertsch, 1981). Activity theory is valuable for conceiving how contexts are constructed as integrated systems and are neither 
"containers" for activity nor simply formed ahistorically by a group engaged in interaction (Lave, 1988). Understanding the functioning and development of an activity system may well include analyzing the relations between individual persons, tools, goals, rules, community, and the division of labor (Engestrom, 1993).

Engestrom (1993) posited three key principles for the analysis of human activity; two are especially pertinent to this study. The first of these principles is that the entire collective activity system can be taken as a unit of analysis: Institutions, persons, goals, and so forth can be best conceived within a network of complex relations, and can be best conceived as highly coconstructed. In this article, we take the entire discussion as a unit and analyze the ongoing coconstruction of individuals, goals, and resources; in doing so, we consider this continuously developed series of interrelations at the microlevel as a dance of (in)stabilities. A key issue that we examine within these multiple relations is the construction and stabilization of institutional goals by both the teacher and the students. As Engestrom wrote: "The pressing theoretical point of our time is the very indirectness of institution building, that is, the indirect or even hidden influence of individual actions on the reproduction of activity systems" (pp. 66-67). Rather than considering the institution as simply a constraint on activity, or as epiphenomenal, such a perspective attempts to describe the construction and maintenance of institutions through activity.

A second principle of activity theory relevant to this work is that the inner contradictions of an activity system can be a key site for analyzing "innovation, change, and development of the system, including its individual participants" (Engestrom, 1993, p. 65). We read the institutional activity goal of performing a science classroom test review, as established by the teacher and corroborated by a number of students, against other goals at play, such as one student's (Brenda's) goal to understand the problem at hand. The analysis suggests how this particular activity system responds to and eventually closes down contradiction and heterogeneity. Adaptation and negotiation in certain areas of this activity system have prompted us to question why other areas, especially conceptual understanding, remain relatively undeveloped for key participants.

\section{METHOD}

\section{Setting and Participants}

Our data is taken from a larger study of discourse practices in a physics class. These data were collected from a class at a public university laboratory school in a small, midwestern city. The school admits students on a competitive basis and describes its purpose as providing a "balanced educational program that enhances the intellectual, creative, social, and physical development of academically talented and 
motivated students." The students in the school are engaged in an accelerated academic program, most of them completing 6 years of schooling in 5 years while fulfilling requirements that include 3 years of science and math as well as 2 years of a foreign language. The racial and ethnic makeup of the student body is $75 \%$ Caucasian, 21\% Asian/Pacific Islander, 3\% Black, and 1\% Hispanic.

Physics is considered to be the more difficult of two science classes offered to juniors; students with less aptitude or interest in science generally take another course. The class assumes a background in algebra, although many of the students are taking calculus concurrently. The videotaped class was composed of 12 girls and 10 boys, most of whom were juniors, although a few were seniors. The racial and ethnic makeup of the class reflected that of the school in general. The teacher of the class, Ramon Hamin (all names are pseudonyms), was in his 3rd year of teaching and was a former civil engineer in his mid-30s. He was originally from Iraq and was a nonnative speaker of English.

\section{Data Collection Procedures}

The first author (Kevin M. Leander) collected the data. Data collection corresponded, by design, with the time frame of a 2-week unit on vibration. His purpose was to follow the class through an entire unit as a participant-observer, learning along with them and watching and recording their responses and interactions. Kevin Leander also tried to engage as a participant by sharing some of his observation reflections with the class on two separate occasions and by serving as a substitute teacher for 1 day.

Kevin Leander recorded classroom talk with two tape recorders, placed at the front and to the side of the class. Midway through the study, he added video-recordings to the audio-recordings in order to capture the rich gestural data as well as the work at the board. The video camera was placed at the back of the room, which was not optimal for capturing all the interactions but was minimally intrusive. In addition, this placement of the camera captured interactions among small groups of students that would have been missed otherwise.

Based on field notes, Kevin Leander initially selected five of the class sessions that contained high levels of interaction among the students and teacher and then transcribed the five sessions. He clarified unclear language, when possible, by cross-checking the two audiotapes with the video. Field notes were taken across the entire course of the study, and he typically stayed after class to talk briefly with the teacher. Furthermore, he conducted two informal discourse-based interviews with the teacher before and during the study to clarify the goals, views, and interpretations of the activity in the class. After the unit was completed, Kevin Leander interviewed 8 students in a semistructured format. Finally, he reviewed a chapter from the class text that was relevant to the unit observed. 


\section{Current Context}

The segment of classroom interaction chosen for this microanalysis is taken from the 4th day of the unit on vibration. The discussion length is atypical for this class; no other open debates were sustained for this length of time, although the teacher does appear to encourage some challenges to proofs and a certain degree of freewheeling activity. However, the various discursive and evidentiary practices displayed here are reflected in other parts of the data. Furthermore, the discourse opens up for display knowledge construction activity that remains tacit in everyday activity, where students are not as open in expressing their views.

The students had primarily discussed simple harmonic motion thus far in the unit and had considered examples such as pendulums and objects vibrating on springs. On the class day in question, Mr. Hamin, the teacher, had announced that the plan would be for him to reverse roles with the students as they solved problems: "Assume that I'm your student, and you're the teacher, and you need to just walk me through to the solution." The day before, the students had organized themselves into five groups for this problem solving, and on this particular day, each group was to select one person as a "student teacher" to present to the class. There were two such presentations by students prior to the discussion analyzed in this article.

The second student problem-solving presentation is significant background. The problem, from the textbook, states that an object at the end of a horizontal spring is struck by a hammer. Giving information on the spring constant, the mass of the object, and the velocity, the problem asks students to discover the frequency, period, amplitude, maximum acceleration, and kinetic energy. At the board, Janet proceeds stepwise through the problem, making use of several different equations, getting occasional feedback from the class and filling an entire section of the blackboard with equations and calculations. Janet pauses in thinking about maximum acceleration and is prompted by the teacher that "maximum acceleration happens when you have maximum force. Maximum force happens when maximum $x$ happens." After a brief exchange with the teacher, Janet solves this part of the problem with $a=F / m$, and then finishes up, without difficulty, solving for kinetic energy. After Janet's presentation, the problem that the teacher presents - which prompts the interaction of this analysis - can readily be interpreted as merely a reformulation of Janet's problem. He appears to have the same physical system and the same point about maximum acceleration in mind. Significantly, however, the students engaged in the following discussion do not follow this correspondence but rather reconstruct and work through the problem using primarily discursive resources and practices very distant from those modeled by Janet.

As Janet is erasing the board, the teacher walks to the front of the class and poses a multiple-choice question for them to solve: 
If an "object" [we will call it a "mass" to distinguish it from other later objects in play] were vibrating back and forth, as if from the door to the window in the classroom, and reached its maximum distance at an end point, it has A. maximum velocity, B. maximum momentum, C. maximum acceleration, or D. maximum kinetic energy?

Through Mr. Hamin's promptings, he makes it clear that the answer is one of the four choices, although students offer another choice (potential energy, a correct but disallowed response) and no possible choice (Brenda: "I think it's a trick question").

In reviewing this entire discussion together on videotape, the teacher said that he selected these four options because the correct response (maximum acceleration) is counterintuitive. That is, stating than an object is accelerating maximally when it is at a standstill conflicts with a typical use of acceleration and, in the teacher's view, requires one to "think systematically." From the standpoint of discourse analysis and science, the conversation is particularly engaging in that the participants discuss a conceptual system that does not simply arise from observing the book of nature, but is imposed on it as a symbolic reality (Driver et al., 1994). Moreover, in this case, the participants observe very little other than their own gestured demonstrations. As such, the natural world itself is created and re-created by them, allowing demonstrations of nature to establish their own dialogic relations to one another.

\section{ANALYSIS}

In the first analysis subsection, we discuss six categories that have emerged from a study of the data as meaningful dynamics. To discuss and illustrate the six categories of (in)stability independently, we draw on the entire 15-min transcript. From this broadly structured analysis, we move into a focused examination of $4 \mathrm{~min}$ of classroom interaction in which we apply the categories as multiple lenses. In this subsection, we consider ways in which the interactions among the various (in)stabilities help us interpret the coarticulations, responses, and movements in the moment-by-moment flow or dance of interaction.

Although we make every attempt to support our interpretations, we consider the most important point not the accuracy or the validity of our interpretations of this particular interaction. Rather, we submit that the most important outcome is in illustrating the value of this kind of interpretive approach which attempts to deal with the interaction in its complexity. Furthermore, our goal in this analysis is not to construct a personal critique of either the teacher or the students, illustrating capricious action, mean-spiritedness, and so forth. Rather, we find the discourse and activity of the participants highly sensible as understood within the unfolding context and as reflecting contrasting perspectives on learning science. 
In particular, from looking at the tape numerous times, we became critical of some of the teacher's actions, which seemed to impede advances in conceptual understanding by some of the students. However, Mr. Hamin acted very consistently and rationally within a framework of mathematical systematicity as the anchoring point for clear thinking and within the institutional goals of efficient coverage of material (particularly important during a test review). Furthermore, by allowing the discussion to continue as long as it did, he demonstrated a sincere desire for students to buy into mathematical systematicity and reap its benefits. Our criticisms, then, are not of Mr. Hamin personally but rather of the overall orientation toward mathematical systematicity as the anchoring point when this is not accompanied by conceptual understanding.

\section{Emergent Categories of (In)stability in the Framework}

We identified the following types of (in)stabilities by analyzing the entire transcript and attempting to develop a broad picture of the work, locations, and movements of the participants. We describe these types separately not because they function as individual entities but in order to develop a working framework for interpreting the complexities within the interactions. By identifying these as types of (in)stabilities, we are interested in both their unstable, shifting nature as activities and their structural nature as more or less fixed forms; the persistence of particular stabilities (e.g., conceptual) despite ongoing instability in other arenas is of great interest to us. Finally, these groups appear to often function as pairs. Focal and conceptual (in)stabilities have to do with coherence in comprehension of and connection among particulars of our experience. One could argue that this is the core of science. Discursive-symbolic and institutional (in)stabilities seek alignment with that which is perceived as socially powerful. Social and affective (in)stabilities seek alignment with peers and with oneself.

Focal. During the course of the interaction, a number of different focal situations are presented as either problems to be solved or evidence for positions held by the speakers. These focal points are primarily constructed through gestures and talk, although an object in the classroom (a pencil), diagrams, and written formulas also come into play. Once introduced, these foci are responsive to past discourse, recombining in various ways and forming hybrids. The first focal situation introduced by the teacher is that of a horizontal harmonic oscillator moving across the room. Something ("it") is briefly and vaguely described by the teacher as moving "all the way to the door- door wide and window, wide." Not only is the system described generally but, through the teacher's gestures, an ambiguity is introduced that becomes important later in the discussion. Namely, when he gestures to indi- 
cate the vibrating mass at the outset, the teacher begins to inscribe a slight upward arc, a pendulum-like motion with his hand in space.

The second major situation is introduced when Mr. Hamin throws a pencil upward to demonstrate its constant acceleration as it rises and then falls. The pencil demonstration is thus a subproof that relates to the horizontal harmonic oscillator only through an abstract principle. However, it is important to note that, over the course of the interaction, Mr. Hamin discusses the rising and falling pencil demonstration more than he discusses the horizontal harmonic oscillator. Part of the reason for this emphasis may be the way in which this demonstration permits him a framework for authoritative discourse based on mathematics (discussed later).

The actual classroom debate begins with Joan's challenge to the teacher: "I still don't buy it- 'cause I think the acceleration would be, like right before it got down." Rather than responding to the pencil illustration, however, Joan gestures a pendulum in space in front of her, thus stabilizing the pendulum as an object under consideration. Michael, seated near Joan at the back of the room, interrupts the teacher and offers his own rebuttal to Joan, which is largely a more animated version of the teacher's original oscillating mass problem: ${ }^{1}$

54 Michael: Right when it's out here ((pushes down with left hand)), the maximum distance out the spring is whipping it back ((pulls left hand to the right, where he is holding right hand stationary)). It's starting out going this way ((points left with right hand)), fairly fast, and then all of a sudden it's going back this way, fast ((points left with right hand)), so it's changing velocity ((points down with index finger of left hand)), like, fully all the way around ((with left hand, forms arc to left and back right, makes three fourths of a circle in space)).

55 Anne: So you have it accelerating, and then back this way? Is that what you're talking about?

56 Michael: Yeah. It's accelerating back this way so much ((points right with left hand)) that it not only stops it from going this way ((points left with left hand)) but also whips it back this way ((points back right with left hand)).

57 Anne: OK.

\footnotetext{
${ }^{1}$ The following transcript conventions were used:

(()) enclose gestures and other explanations of activity in italics

(..) each period represents a 1 -sec pause

$=\quad$ connected speech

[ ] overlapping speech

(unclear) absent or unclear word(s)

Now emphasized speech
} 
((Brenda's question in turn 58 comes in during the middle of Michael's utterance in turn 54. It is unclear how much of the sequence she was paying attention to. Her question is in a loud voice while facing the teacher.))

58 Brenda: But wouldn't the maximum acceleration be after, like, $g$ effects it, and the spring is pulling it- right like after the spring is done pulling it back

59

60 David:

61 Brenda: And g is done, like, pulling it down? Like- like if you had- remember that- a pendulum, it's pulling up. Like if you have the s: (.) I- I don't know- are we talking about a spring, or a pendulum, or what? (..)

Michael introduces a spring into the teacher's description, which is "whipping [the mass] back" (turn 54). Brenda, picking up on Michael's comment, briefly attempts to stabilize the system: "Are we talking about a spring, or a pendulum, or what?" (turn 61). Significantly, Brenda's question about what situation is at hand is not addressed; space to stabilize the situation is not opened within the interaction. Rather, as Susan interjects, aligning with David, Brenda presses on in her argument:

63 Susan: Well, if you have a pendulum, and it's down at equilibrium, then $g$ isn't really pushing it, it's- it's not going to get force, except downwards=

64 Brenda: But $g$ is pulling it down ((with index finger of left hand, draws a line down in space)), and then the force of the string is making it come back this way ((makes arc with index finger to left of this imaginary line, retraces this motion twice; the second arc is smaller than the first; at "this way" marks out back-and-forth horizontal motion with right index finger)), so wouldn't like, the, I just think the acceleration is like, just like logically, in my mind, it would be right where ((draws semicircle in space with right hand toward herself)) it's done((points straight down quickly with right index finger, then brings closed hands together in front of her, and pulls them into her)) all the forces are done pulling it, so everything combined ((swings arms out and then brings hands together, slaps back of right hand in palm of left twice)) at that one point.

Brenda's argument is suggestive of the ways in which focal hybridity is formed across the interaction. Although Michael first describes the object as "it" and then 
aligns the force with the "spring" (turn 54), two lines later, he uses the reference "it" for both the object and the spring. The vague and potentially conflicting indexicality of "it" contributes to the focal confusion in the discourse, but at the same time, this vagueness provides a loose structure for Brenda's counterargument involving the pendulum. From Michael's discussion of the force of the spring, which "whips it back this way" (turn 56), Brenda appropriates the basic shape of her argument: "and then the force of the string is making it come back this way" (turn 64). This loose argument structure is gestural as well as discursive. Brenda is responding to Michael's hand gestures that demonstrate opposing horizontal force (turn 56) when she sketches her own line in space downward for "g" and also gestures the "force of the string" in an arc (turn 64). Still more suggestive, a few lines earlier, Michael also gestures downward, with the index finger of his left hand, and forms a large arc in space with the same hand (turn 54), which may itself be responsive to the gestural ambiguity in the teacher's introduction of the problem. Both the arc and the downward motion are integral to Brenda's counterproof with the pendulum as a focal situation (turn 64).

Later (in)stabilities in the problem situation include Michael's vertical reorientation of the oscillating spring and Charlene's concretizing of a pendulum through a sketch. When this attempt fails, Mr. Hamin draws on everyday occurrences and constructs a brief narrative about a mother who is controlling her baby with a "rubber band" that is tied between them: "The farther away the baby is, the more force the mother will force the baby to come back to her?" Later, after Brenda remarks, "That analogy kind of missed me," Mary, another student, also draws on everyday situations to convince Brenda by discussing a speedometer, "Let's say you want to get at 30 miles per hour, if, when you first push the gas pedal, the needle like jumps up."

Conceptual. Even when individuals seemed to align around the same focal situation, there were apparent misalignments in their ways of talking about these situations. We take these as evidence for differences in conceptualizing the focal situation. In most cases, conceptual (in)stabilities remained implicit, without explicit recognition from students or the teacher. In addition, in most cases, conceptual instability appeared to occur at the interpersonal level more than at the intrapersonal level. For example, it seems that the teacher and Michael viewed the spring or gravity as initiating agents (Brown, 1993, 1995) and the object as simply affected by the spring or gravity. The focus thus was on the agency or causal power of the spring or gravity. By contrast, Brenda seemed to view the object as an initiated agent - the agency (signaled by motion) is the most when the force has accumulated in it. Thus, Brenda seemed to focus on the "power" (or "motion" or agency) of the object rather than on the spring's or gravity's ability to cause a change. She consistently maintained that the maximum acceleration would be at or 
just prior to the point of highest velocity, when all the forces "are done pulling it" (turn 64). This difference in focus was never explicitly recognized and may have contributed to Brenda's continuing inability to align conceptually with Michael and the teacher.

At one point, Mary seems to make sense of the idea of maximum acceleration at maximum distance by virtue of the "snapping back" of the baby:

Mary: ((Turns around in chair to face Brenda from seat in row ahead)) It's gonna be like- like- when it- eventually when it goes too far ((moves hand right hand away from body)) it's gonna snap back ((pulls arm back quickly; her body jolts back and her head rocks, as if pulling with a great force))=

160 Brenda: I know, but my- I don't understand why- why wouldn't it be like- if it's going from zero, till right when it gets to you, is the baby at zero, like right before it gets snapped back, and it's at=

161 Terry: But it doesn't matter if it's zero or not because it's the change that matters ((Terry is seated next to Brenda and just turns head to speak with her, shoulders squared to front)).

162 Brenda: OK, but that's what they were- it doesn't matter- then you put him like, to- going fast ((makes two arcs in space with pencil in right hand)), then why wouldn't it be, the highest acceleration right before it goes- gets really fast ((points at a point in space directly in front of her )), like right before it gets to the very fastest point ((repeats pointing to space in front of her $))$. Wouldn't (.) I don't understand why.

163 Mary: Because the change wouldn't be the biggest. If it starts from zero and goes out ((moves hand from in front out to left side $))$, then (.) I don't know ((shrugs shoulders)).

Mary relates to the almost instantaneous motion as a way of making sense of an instantaneous maximum acceleration. However, even though Mary's perspective focuses on the agency of the object (as does Brenda), this explanation remains unconvincing to Brenda. For Brenda, the snapping is not as salient as the fact that it would be going even faster at a later point; therefore, the acceleration could not be maximum at that point. Despite this interaction, both Brenda and Mary maintain relative conceptual stability and appear to rearticulate (and perhaps reaffirm) their divergent understanding in a later exchange, when Mary attempts to convince Brenda using the illustration of the "jumping" of the speedometer needle in a car.

Brenda's inability to realign conceptually is not due to a failure to engage. Throughout the discussion, she mentions not understanding or trying to understand or make sense 13 times. For example, she does so in response to the teacher's exposition about $F=k x$ (thus the maximum force at maximum $x$ ). In another ex- 
change, Brenda states "but that doesn't make sense- like- physically," and the teacher responds, in a rather exasperated tone, "Why not?" This vignette is characteristic of Brenda and the teacher's interaction throughout the 15-min segment. The teacher mentions understanding twice and making sense twice, but each time he casts understanding or making sense in a somewhat negative light with respect to the "right way of thinking," which is mathematical and systematic. The conceptual misalignments between Brenda and the teacher are critically important, and they offer a ready explanation of the way in which the two appear to talk past one another. Equally important, however, is the way in which this conflict brings to light the contrasting beliefs that Brenda and Mr. Hamin hold about the process of developing conceptual understanding itself.

Near the end of the discussion, the teacher directly addresses the classroom interaction and its relation to "systematic thinking, in science." When Brenda objects to his interpretation, the teacher outlines his beliefs about the process of coming to conceptual understanding:

165 Teacher: Let me point out here a very dangerous trend that's happening. The dangerous trend that's happening is that you have a formula- ((points to formula on board $)$ ) that we systematically derived, and we believed in our derivation ((points over shoulder to board while facing class)) from the beginning. Now we have a formula ((faces board, points to formula)) that tells us that the maximum acceleration happens when this is maximum ((points to parts of formula in sequence while speaking)). The mass is constant- and the spring constant, is constant ((pointing to $\mathrm{m}$ and $\mathrm{k}$ in last fraction of formula)). The only thing that's changing is $x(($ points to $\mathrm{x}))$. So the maximum acceleration happens when $x$ is maximum ((points to $\mathrm{A}$, then $\mathrm{x})$ ), which means when $x$ is equal to $A$ ((points off into space)). That's when the velocity is zero. The systematic derivation is telling us that the acceleration maximum happens at a point when our intuitive thinking ((holds hand to chest while saying "our")) right now is saying no, and what we are doing now, which is a dangerous thing, we are preferring our $\underline{0}$ :wn intuitive thinking- ((points to head)) over the systematic thinking, in science ((points back to board $))$. That's very dangerous.

168 Teacher: What I expect you to do i:s- this must be right ((points to board)), and I cannot understand it. You keep vibrating 
around it ((makes circular motions with hand)), vibrating around it, until you solve it. You don't just discard it=

The teacher interprets the "dangerous trend" of the discussion, and by implication, Brenda's approach to the problem at hand, as a preference of intuitive thinking over systematic thinking. In the teacher's view, conceptual understanding is attained by giving assent to a particular end point, provided by scientific conclusions, and appropriating the scientific formulas or arguments necessary to move toward this end point. His perspective on understanding could readily be termed teleological, in that a clear end in view guides appropriate steps to take as well as beliefs about the self with respect to the authority at the end. In contrast, Brenda expresses a desire to "understand both" intuitive thinking and systematic scientific thinking (turn 167). Her perspective on understanding could be termed dialogical, in that she expresses the belief that intuition and science will somehow coarticulate and coenlighten one another on the path to unclear outcomes. These contrasting perspectives suggest how Brenda and the teacher are misaligned not only about simple harmonic motion but also about the nature of how one comes to an understanding. Furthermore, these divergent process orientations are reflected in the discursive-symbolic resources used in the discussion as well as in the constructions of institutional goals by Brenda and the teacher (discussed in the following sections).

Discursive-symbolic. Largely, the teacher stabilizes his illustrations and demonstrations with mathematical equations, moving away from them on occasion but returning to them when he senses that the direction of the discussion is moving too far away from his purposes. The students, on the other hand, discuss evidence and meanings in relatively varied ways. Although the teacher's discourse is most often authoritative through mathematics (hence our term mathematical-authoritative), the students typically operate with a belief that situations themselves, the world around them, and their stories will provide evidence that will be internally persuasive. Because of the way mathematical reasoning is typically used in schools (i.e., as an efficient and accurate way to get correct answers), this category is closely related to institutional stability. Although the teacher's maintenance of institutional stability is primarily implicitly (albeit strongly) evident, he turns repeatedly to mathematical or systematic reasoning as a point of stability, using the terms systematic or systematically four times.

At the outset, Mr. Hamin remarks that the students should solve the problem through memory of a past problem and resulting formula:

29 Teacher: Remember, she just solved for it. Maximum acceleration happens when the maximum force happens. Maximum force happens when the maximum $x$ happens; maximum $x$ happens at $A$. 
The mathematics from the past problem should simply be relocated in the new situation. Sensing doubt from the students, the teacher moves into the rising and falling pencil demonstration (projectile motion). This demonstration instantiates mathematical-authoritative discourse as the teacher brings together the current problem, a material object in space, previously learned scientific formulas, and numerical values in an argument for constant acceleration:

74 Teacher: Fifteen. One second later, it was fifteen ((repeats the same motion but in the space above the original space, with a span of about $1 \mathrm{ft}$, with right hand in space over left hand)), now it becomes?

75 Brenda: Five?

76 A few, at intervals: Five.

77 Teacher: One second later, it was five, now it becomes? ((Shifts left hand up and, reaching up with right hand above left, shows space of about 6 in. and then inscribes an arc in space, as if motion has reached peak and is now coming back.))

78 Anne: Fi:ve?

79 Teacher: Minus five- it was going five upward, reached the summit, now it's zero, it's minus five ((repeats motion of moving upward with the right hand, making arc, and returning to location such that both hands are at a parallel point in space)). The rate of change- they didn't care ((moves both index fingers back and forth, hand about at parallel point of last gesture)) of what happened in between. It was going upward, now it's going downward ((makes up and down arc with one hand)) it was going upward faster ((moves left hand up, away from right)) now it's going upward slower ((continues to move left hand up, at slower pace)) (..) OK? The rate of change is ten meters per second every second $=$

Note, however, that even as the teacher mobilizes numerous resources and affirms mathematical-authoritative discourse, there is still some instability in his discourse with "they didn't care of what happened in between" (turn 79). This discursively unstable animation of the system with feeling and intention could be interpreted in various ways. One plausible interpretation is that the teacher is attempting to bridge over to the students' means of proof giving through animated narratives, a movement more completely evidenced in the following account.

After $12 \mathrm{~min}$ or so of discussion, the teacher makes his strongest departure from his systematic means of proving with mathematical-authoritative discourse. Here, he creates a story from everyday life, bridging over from the world of physics to 
the world of everyday markets, babies, and mothers. The illustration of a mother controlling a baby in a supermarket by way of a large rubber band seems to have some limited success with Mary but not in the case of Brenda. The teacher's shift in position at this point appears to be one last effort at presenting evidence to Brenda, acknowledging the narrative mode of operating that Michael has introduced into the debate. Like Michael's narrative, this one has drama, lively action, and human animation carried to an even greater extreme. However, when the situation is questioned as a drama with debatable outcomes and interpretations, the teacher returns and stabilizes the discussion again in mathematical-symbolic discourse:

164 Teacher: The acceleration of the baby, is equal to the force of the rubber band, divided by the mass of the baby. If the baby is skinny, the mother (unclear) than the baby.

Institutional. When the illustration of the mother with the baby fails to convince Brenda, the teacher returns to the formulas on the board as an anchor for the discussion and argues that a "very dangerous trend" is happening. The teacher's warning clearly echoes his continual orientation toward mathematical-authoritative discourse and also illustrates an ethic of working in science class whereby one begins with a problem solution, believes it, and encountering difficulty, assumes that this difficulty is within the self rather than the solution. This teleological orientation to the classroom activity, which also figured in the (in)stabilities of perspective on the process of conceptual understanding, contributes as well to the teacher's and students' contrasting relations with institutional goals.

This classroom period is scheduled as a test review, and Mr. Hamin orients both himself and the students around this goal. He expresses in several ways the importance of moving through a given amount of material to assure that the students are prepared for the exam. At the same time, on this day, he chooses to open up the class to more student control, having 2 students at the outset "be the teacher" in presenting two separate problems. Thus, the teacher's position can be interpreted as somewhat unstable overall with respect to institutional goals: He is both oriented toward the closure or stabilization of a knowledge set for an exam and directed toward a more open, institutionally unstable approach, ostensibly for student involvement and understanding. However, although institutional instability might describe the format of the overall original activity of students serving as teachers (a format he shifts out of after the first two problems), there are a number of ways in which the teacher asserts institutional stability. The current problem is only the third problem being considered for the review and, as noted earlier, is most likely intended by the teacher as simply a reformulation of the problem preceding it. After the teacher opens up the discussion, he also attempts to close down the talk and bring closure just 2 min into the discussion: 
39 Teacher: If you are taking any multiple-choice tests, that's a very potential question.

The remark and its early expression indexes the time pressure of the current situation and its institutional meaning - to know potential answers to potential questions. Furthermore, the expression "any multiple-choice tests" locates the purpose of the current activity within educational institutions (e.g., other classes and testing companies) extending well beyond the current context. Another attempt at closure of the argument is expressed in the teacher's final gesture (palms forward, then hands folded) following the rising and falling pencil demonstration. Finally, the teacher brings this discussion to institutional closure while students are still engaged in lively discussion with each other about the central ideas of acceleration and simple harmonic motion, reminding them that only $8 \mathrm{~min}$ of class are left.

In addition, institutional goals are reflected in participants' preferred terms for describing ongoing activity. For example, the teacher asks "Do you buy it?" several times, indicating a commitment to institutional stability in which it is important for students to buy into authoritative claims. Interestingly, Brenda says several times that she "buys it" or "believes it" but does not understand it. Brenda apparently wants to preserve some degree of institutional stability but not at the price of conceptual stability.

Social. In this section, we explore how participants construct alignments or misalignments with one another. Brenda's challenge of the teacher's initial position, for example, can be viewed on both the institutional and the social level. Her countering of the teacher's position is constructed through a social alignment with Joan, who is the first to challenge the position, with "I still don't buy it," but soon drops out of the conversation:

Joan: I still don't buy it- 'cause I think that the maximum acceleration would be, like right before it got down ((moves pen down in a small arc from her right side to her left while pointing with forefinger of left hand at bottom of this arc; holds in this position momentarily)).

43 Teacher: Just right before $=$

44 Joan: Well, I don't know but- it- I don't understand ((drops hands to table)) why it would be

45 Teacher: Okay- let's- let's think systematically

46

47 Brenda:

[

I don't understand it either

A similar alignment occurs 10 min into the discussion, when David finally expresses his agreement with Brenda's challenge, and Brenda recognizes this social 
alignment with a "Thank you!" Several in the class laugh, responding to the small vindication of Brenda's arguments through David's show of solidarity. In this occasion, the social alignment counters institutional stability; in other interactions, social alignments stabilize the institution. Social alignments can function as displays of solidarity or the construction of networks of belief among persons, whereas misalignments may reflect instabilities at other levels (e.g., conceptual and focal).

Socially speaking, Brenda's argument with the teacher's problem solution becomes increasingly unstable as she rejects the authority of the evidence her teacher and peers present to her. Michael's and Charlene's own positions within these occasions of intervention are intriguing instances of social instability as well. So as not to overly align with the teacher, thus misaligning with the other students and identifying himself as a "nerd," Michael prefaces his remarks with protestations of ignorance:

114 Michael: Well, I think- I'm not claiming to be an expert, but, or to- necessarily even have a clue ((laughs for a few seconds; others in class (augh)) ...

Charlene, on the other hand, seems to use a historical and social alignment (her friendship with Brenda) as part of an authority of intervention for Brenda and yet also to rejoin the group and reject Brenda's social and institutional position after she feels threatened by the discursive and conceptual instabilities that Brenda raises:

141 Charlene: ((Looks back while walking away)) How are we supposed to explain it to you in your own words? You like understand but you don't understand.

142 Teacher: OK, let's imagine you

143 [

144 Brenda: Yeah, but I don't understand it

145 Charlene: You understand but you don't believe it.

Michael's and Charlene's responses demonstrate a more nuanced and historical sense of social alignment that seems as powerful, although less readily visible, as the ongoing construction of social networks. Michael's response and disavowal of authority suggest that he is responding both to a social sense of being a student as opposed to a teacher as well as to the meaning of being one kind of student versus another (i.e., being cool rather than a nerd). His negotiation of these boundaries prompts him to talk not only quite confidently about the science but also about his lack of scientific authority within the same stream of discourse. Charlene's close friendship with Brenda shapes her social positioning within the interchange in a 
different sense, in that she must negotiate not a historical set of general roles alone but the borderlands between friendship, evolving classroom social alignments of belief, and historical as well as evolving institutional agendas of recognizing the teacher's authority and moving through a test review. The interplay of situated, moment-by-moment network formation with more durable and historical roles and relationships is highly complex, and we recognize that the social category is not one dynamic but is itself multidimensional. At the same time, we believe that some of the embedded or inflected aspects of the social category as a broad dynamic are foregrounded by mapping its complex relations to the other categories within the flow of interaction.

Affective. Affective responses are closely related to social alignments and misalignments but also are linked to other arenas, such as the conceptual, as feelings of excitement in understanding or frustration in confusion are expressed, or the institutional, as institutional norms are disregarded. For example, Charlene excitedly says, "I got it," and Mary says, "That makes a lot of sense," after Michael's and the teacher's explanations, respectively. Charlene also expresses frustration at problems pointed out in her insight, as discussed earlier. The teacher also expresses frustration at Brenda for not understanding "physically."

Brenda's emotional response to the ongoing situation can be interpreted from both explicit verbal responses and nonverbal responses. Although she earlier challenges the teacher in a loud voice and asserts her argument with both gestures and talk as Mr. Hamin counterchallenges through mathematical-authoritative discourse, Brenda's voice softens and is more hesitant. Furthermore, during this segment and in a later one, in which the teacher is still more authoritative, Brenda's activity with her hands begins to suggest withdrawal. Brenda's gestural demonstrations of the physics begin to be increasingly punctuated with her preoccupation with a small toy. Brenda even begins to gesture only with her right hand while her left hand turns the toy, whereas in earlier gesturing, both hands were actively engaged in embodied proof giving. This bodily disengagement, accompanied by a preoccupation with a personal object, distant from schooling and physics, is suggestive of Brenda's affective disengagement from the interaction.

The greatest emotional upheaval happens near the end of the discussion. When Brenda states that she is "trying to understand both" intuitive thinking and "the systematic thinking, in science," Mr. Hamin responds:

168 Teacher: What I expect you to do i:s- this must be right ((points to board)), and I cannot understand it. You keep vibrating around it ((makes circular motions with hand)), vibrating around it, until you solve it. You don't just discard it=

169 Brenda: I didn't discard it, that's why I'm asking! 
171 Teacher:

[ You don't say- I don't want it, it doesn't make sense $=$

172 Brenda: If I discarded it, I wouldn't have asked to try and understand.

In this interchange, Brenda and the teacher both speak with a high degree of emphasis and tension in their voices, displayed also by their rapid exchange, latching and overlap of lines, and higher volume. The teacher's use of "discard" reveals something of his frustration, which can also be inferred from the fact that Brenda does not buy the solution he has presented, despite his multiple efforts of proof and those of Brenda's peers. His rephrasing from "discard" to "You don't say- I don't want it" suggests that Mr. Hamin is attempting to modulate his frustrated reproach, just as Brenda's repetition of "discard" in her rejoinder suggests how she has focused on the strength of the term. Finally, because Brenda has made a long sustained effort to understand the problem, the doubling of the frustration of these failed efforts by being accused before her peers of "discarding" the given solution can be readily inferred.

\section{A Multidimensional Analysis Through the Framework: The Dance of (In)stabilities}

The following analysis represents 4 min of classroom interaction, which begins approximately midway into the 15 -min discussion analyzed previously. We divided the segment into three episodes according to the principle participants within them. Brenda and the teacher are the principle participants in the first episode, whereas in the second and third episodes, Brenda primarily interacts with other students. In all three, these interactions are the focus of classroom attention.

Episode 1. The first episode is very brief; the entire interchange follows:

96 Teacher: In this case we have a spring. Do you buy that the acceleration is equal always to the force divided by the mass? ((writes equation on board: $\mathrm{a}=\mathrm{F} / \mathrm{m}=\mathrm{kx} / \mathrm{m})$ )

97 Brenda: Mhm ((softly)). Sure, sure.

98 Teacher: Do you buy that? ((holds right hand up with palm up ))

99 Brenda: Sure ((spins toy around pencil)).

100 Teacher: Do you buy that in the spring the force is equal to $k$ multiplied by $x$ ? Do you buy that? ((Points to equation with left hand))

101 Brenda: Ye:ah. 
102 Teacher: Do you buy that the bigger the $x$ ((points to $\mathrm{x}$ on board with left hand)), the more force in the spring to pull ((pulls left hand away from board)) the object backward?=

103 Brenda: But that doesn't make sense- like- physically.

104 Teacher: Why not?

The teacher's stabilization of "this case" can be read as a desire to fix a common object of perception for authoritative purposes. It drives the dialogue away from the falling pencil demonstration and the pendulum. At the same time, the stabilization of the spring is dialogic to different interactions. Prior to this, Brenda has just challenged Mr. Hamin's arguments about the falling pencil, which he has presented for the second time: "I still don't understand how it would be the highest at the top then." Brenda's comment illustrates how she is attempting to read the falling pencil demonstration as an instance of the acceleration concept presented by the teacher as the original problem. Rather than responding directly to these conceptual and focal instabilities, the teacher represents the "case" by a single object, the spring. Although the discussion has proceeded for several minutes, this is the first instance in which the teacher names the spring as participating in the situation. However, Michael introduced the spring earlier in the discussion in his first explanation of the focal situation. Mr. Hamin's coconstruction with Michael evidences the social and focal alignments between them. These alignments are further supported in the next episode and by the general fact that Michael reinstantiates a situation closer to the original problem more often than does the teacher.

Moreover, this stabilizing of the spring effectively shifts the discursive code back toward the teacher's primary form of authority - mathematics - which is constructed here around spring constants, mass, force, and so forth. Mr. Hamin's three primary questions are actually little more than parts of the formula $(a=$ $F / m=k x / m)$ he has written and gestures toward on the board, introducing them with the phrase "Do you buy that?" Significantly, the teacher never represents the scientific situation on the board but only fixes mathematical equations in this space. (The situation most stabilized by the teacher is the falling pencil, a situation formed through gesture, brief "demonstration," and the materiality of the pencil itself.)

The striking repetition of "Do you buy that?" (five instances), in a declarative tone at slightly louder volume, evidences the teacher's irritation at Brenda's resistance to proceed in the class in a way that supports both the institutional stability of moving through the problems and the authoritative stability of accepting mathematical systematicity. Institutional stability and mathematical discursive code are coarticulated and supported; Brenda disrupts both by challenging the situations with one another and against her perspectives drawn from everyday life. The episode illustrates the teacher's belief, which he clearly articulates later, that students are supposed to begin with belief, or "buying" the formulas, and work toward an 
understanding of them (i.e., a teleological approach). If doubts exist, then students are to turn these doubts back on their own understandings rather than on a given formula, which comes from science and is further "systematically derived" in the classroom.

In response to Mr. Hamin's mathematical discursive code, Brenda has, in Bakhtin's sense, no "answering words" (Voloshinov, 1973, p. 102). The exchange is an excellent illustration of how Brenda's attempt to construct an understanding through internally persuasive discourse is shut down by the teacher's authoritative discourse. In response to the equations that are fixed on the board, in the textbook and in the teacher's position, Brenda cannot respond to the rhetorical questions except in the affirmative. There is no room for movement - "acceleration is equal always to the force divided by the mass." Brenda's responses are, however, indicative of a movement of her affective and social instability within the classroom. From being more openly and gregariously engaged, Brenda turns inward, softens her voice, and turns her gaze often away from the teacher toward a small rubber toy, which she spins around her pencil. This is the most emotional interchange thus far in the discussion, and Brenda is quickly affected by it. However, she is still engaged enough socially and conceptually to repeat the ongoing, stable question that is troubling her: The teacher's answers do not make sense "physically." The teacher's response of "Why not?" is illustrative of how the two speak past one another during the entire discussion. His discursive code, as well as the institutional agenda that it supports and operates within, does not respond to her code and goal of understanding.

Episode 2. After the teacher's attempt to persuade Brenda by way of mathematical discourse, Michael tries to mediate between Brenda and Mr. Hamin by responding to and building on the teacher's construction of the situation. Michael and the teacher coconstruct situations to a remarkable degree. Whereas in the last episode Mr. Hamin stabilized Michael's spring, in this episode Michael is responsive to the teacher's pencil demonstration, the original horizontal oscillator, and the spring that they have stabilized together. From these, he constructs a hybrid situation, a spring-based oscillator that is oriented vertically:

107 Michael: Here, (.) OK. (..) You've got your thing attached to a spring ((points to palm of left hand with right)), going up ((pulls cupped right hand away from left)), pretty fast, ((points quickly up with right index finger)) where it's at the maximum height ((shows grasping motion with right had at the up position)). It's s- still trying ((points up again two times, with right hand beyond the space indicated with grasping hand)) to go this way? And- the force moving it back down ((points down 
toward table with right hand)) this way toward the spring is so much that it not only stops it going up ((points up)), but it's also moving it back down? $(($ points down $))=$

This focal hybrid is also interesting from a perspective of conceptual stability. Like Brenda, Michael is able to accommodate shifts within the situation he is considering and to maintain a relatively stable conceptual view. Although Michael's new situation is different conceptually from the original problem, because it involves the constant gravitational field as well as the changing force from the spring, his conceptual viewpoint is stabilized by viewing the spring, and in this case the spring and gravity, as initiating agents (Brown, 1993, 1995) and the oscillating object as simply affected by them. Like the teacher, Michael focuses on the causal power of the spring or gravity. By contrast, Brenda continually focuses on the agency of the oscillating object, in which its agency (signaled by motion) is highest when the force has accumulated in it:

108 Brenda: Well, so then if it's gonna stop it, how can the acceleration be most there? ((Mainly faces forward but looks over her shoulder at Michael; continues to play with toy.))

109 Michael: Because the acceleration has all been downwards ((points down)). It's not acceleration going upwards ((points up))

111 Brenda:

[

But see what I'm

saying is if it's going down ((points down with pencil, quickly, at an angle toward herself)) and the spring is pushing it down ((makes another quick motion down with right hand, which is holding pencil)), why wouldn't it be greater after the spring's pushed it some? ((indicates a span of a few inches with hand while moving it down in small arc; moves pencil end to toy, which she has been playing with in left hand while making these motions with right)) (..)

Brenda's challenge to Michael's explanation illustrates how they speak past one another conceptually. Brenda's and Michael's conceptual understandings remain stable and separate in the discussion. His vertical reorientation of the oscillating system may even assist Michael in stabilizing his conceptual view. In his earlier description, he concentrated on the intensity of force within an interval and on the force inward toward the equilibrium point of the spring. His remark "the acceleration has all been downwards" (turn 109) adds gravitational force to his earlier conceptualization of the force involved as the object changes directions within an interval "like fully, all the way around" (turn 54). Michael appears to understand something of Brenda's difficulty with understanding acceleration, responding to 
her reasoning "after the spring's pushed it some" with "that would be the ((softer voice)) velocity." However, this distinction is only noted, not explored, and is thus left to remain tacit. Although Michael and Brenda maintain and even build on relatively stable but strikingly different conceptual viewpoints, the conversation does not move to explore the ways in which, publicly and interactively, there is a great degree of conceptual instability. Like the teacher, Michael does not directly respond to Brenda's question but moves to prove once again his point of view through a rearticulation of the situation as he sees it:

114 Michael: Well I think- I'm not claiming to be an expert, but, or to- necessarily even have a clue ((laughs for a few seconds; others in class (augh)) but the way I understand it is, the ac:celeration is the change in velocity, so you've got, your velocity that's going upward pretty fast ((points up)), and then the spring- um((fixes space with right hand in cupping motion at up position)) the acceleration that's pulling it from going upward ((points up)) pretty fast to going downward pretty fast ((points down)), all at the same time.

Michael does not fully take up Mr. Hamin's mathematical discursive code to arrive at meaning; instead, he develops an understanding through considering and constructing the focal situation itself. In this way, his meaning making resembles Brenda's more than the teacher's, and yet, there are important contrasts between the 2 students as well. Two significant aspects of Michael's discursive code appear to aid him in constructing meaning by moving through the situation. First, Michael's conceptual stability, grounded in viewing the spring and gravity as initiating agents, is buttressed by the narratives he constructs, stories that are animated with drama, personified agency, and lively motion. The object is going "pretty fast," the object is "s- still trying to go this way," and the force is so much that it "not only stops it going up, but it's also moving it back down." Although Brenda largely constructs arguments as responses to situations, Michael's code fleshes out a story through the situation, with opposing forces, effort, and speed. Another important aspect of his discourse is Michael's constant and distinct gesturing of opposing forces and directions, end points in the system, and agency and effort on the part of the moving object. For example, in the previous segments, he points upward three and two times, respectively, before pointing downwards, to demonstrate how the "force moving it back down this way toward the spring is so much that it not only stops it going up, but it's also moving it back down?" (turn 107). Michael's gesturing contributes to the construction of narrative-based, animated engagement and proof giving. Brenda, on the other hand, is less bodily engaged in proof giving, just as she remains less attached to narrating the construction of a single situation. Rather, Brenda remains somewhat more distanced from a particular 
situation and poses a stable conceptual question ("Why wouldn't it [the highest acceleration] be right before that center point?") at a more abstract level.

Michael's talk of "not claiming to be an expert, but, or to- necessarily even have a clue" is a rich instance of his negotiations among conceptual, social, and authoritative stabilities. At the conceptual level, Michael is reflecting on "the way [he] understand[s] it," relating how he has come to his own understanding, which may or may not be the correct or common one. Michael's expression of uncertainty is slight in that he does not consider alternatives or seem to be struggling with his ideas. Still, the expression of doubt may be regarded as a "conceptual nod" - Michael recognizes that his knowledge has limitations and that other possibilities may exist.

Socially, Michael's utterance is a response to the increased attention that has become focused on him as a speaking authority. Even Brenda, who speaks over Michael's earlier illustration in addressing the teacher, listens to and questions him (although her bodily orientation is still toward the front of the room and toward the teacher, whereas Michael is seated behind her and to the left). Michael has also become more aware of the filming presence at the back of the room. Within the interchange, Michael is also responding to his previous rather sheepish censure of Brenda: "That- that would be the- ((softer voice)) velocity ((smiles, glances at camera, and makes inaudible comment))." This foray by a student into authoritative discourse brings immediate reaction from the class - many students laugh and several make motions that this distinction is too technical. Michael surmises immediately that this breach with a student voice will cost him in terms of social alignment with classmates unless he acts quickly to mend it, and he quickly casts himself as a regular, nonexpert, sometimes clueless student. The wording of "[not] to- necessarily even have a clue" especially borrows from common student discourse. Michael's attempts to negotiate his social, authoritative, and conceptual locations are also evident in his attempt to repair the social breach. After "the way I understand it is," Michael chokes a bit on the word "ac:celeration." The scientific language implicates Michael into a precarious social position with respect to the class, but his disavowals provide him a way to move in contrasting directions, expressing a divided subjectivity.

Episode 3. After Brenda fails to be convinced by Michael's illustrations, she raises her hand to engage the teacher. Charlene, who is a good friend of Brenda's and is seated near the front of the class, has a brief side conversation with Mr. Hamin, apparently asking him about the differences among the problem situations presented, to which the teacher replies, "The pendulum is exactly the same as the spring." Charlene then asks permission to intervene:

118 Charlene: Brend, wait, I got it- can I say something? 
Brenda: Yeah. I'm not arguing 'cause it's obvious the point's right, I just don't understand it.

Immediately, Brenda responds to Charlene's involvement, and her assumption that Charlene is about to argue suggests that Brenda is feeling socially and emotionally threatened. For Brenda, the problem is "obvious[ly]" right not because her conceptual understanding has changed but because she is alone in continuing to challenge it and because her good friend has now joined in the proof giving to counter her position. Like Michael earlier, Brenda gives a conceptual nod to other possible solutions, a limited assent motivated not by conceptual struggle but by social instability. Brenda's statement of trying to understand is a defense of her social position. Charlene walks toward the back of the room and takes a seat at Brenda's table, facing Brenda, and begins to sketch a pendulum. Significantly, this is the first time in the discussion that the situation has been stabilized with a sketch.

120 Charlene: If you have a pendulum ((begins to draw a line in space at an angle down to the right in front of her)) (..) Can I do a diagram?

121 Teacher: You can come closer to Brenda, so you come closer to theVCR ((Charlene gets up and walks to Brenda in back of class, laughs)).

122 Charlene: (..) If you have a pendulum- ((begins drawing a pendulum in Brenda's notebook when seated across from her at the table)) $\mathrm{OK}$, you have a pendulum- at this point over here $x$ equals $A$ ((turns notebook so that Brenda can see more easily while writing and orients their work more side by side)), so therefore if $x$ equals the velocity equals zero, right? ((looks at Brenda))

123 Brenda: (unclear)

124 Charlene: Shut up ((joking tone)). Right?

125 Brenda: Yeah.

126 Charlene: So then here ((indicates point on diagram)), and we know that at- $v$ nought or whatever, in the middle ((draws line up and down $)$ ), this is the maximum velocity ((looks up and waits for agreement)) (..)

127 Brenda: Yeah

128 [

129 Charlene: Right? OK, so therefore, the acceleration- to go from no velocity to the maximum velocity ((shows two points on diagram $)$, doesn't the acceleration have to be maximized to get from here to here? ((indicates two points on diagram again)) So then it's like right in here ((circles part of diagram)). 
Importantly, Charlene selects a pendulum, which has been out of the discourse for some time but is the situation that Brenda focused on early in the discussion. Charlene further stabilizes the pendulum by sketching and labeling it. It is also important that Charlene begins to take on the teacher's mathematical discursive code: "so therefore if $x$ equals the velocity equals zero, right?" However, this code and its social authority, taken up by the person of Charlene, is destabilized by Brenda's inaudible comment, and Charlene momentarily picks up on this peer-based, teasing banter by jokingly saying "Shut up." Brenda and Charlene momentarily slip out of the teacher-student subjectivities they have taken up and become sparring friends.

Charlene's effort to patch together a conceptual view is intriguing. Charlene shifts the language of the problem from noun phrase to verb, from "maximum velocity" to "maximized." This language borrows from everyday ways of speaking about maximizing, for example, one's energy, profit margins, or clothes detergent power. Acceleration is at a maximum state at the stationary amplitude of the system because it has to be "maximized" across the range of motion. Hence, maximum acceleration is both a cause and a characteristic of the velocity; the focus is no longer on a particular point but on a zone.

When Brenda challenges Charlene's explanation, offering a conceptual view that Brenda holds stable throughout the entire discussion (that highest acceleration would be at or "right before" highest velocity), David, who is silent throughout most of the discussion, aligns socially and conceptually with Brenda:

130 Brenda: Yeah, so my point is- but why is it right there ((draws point on diagram)), he said at the very highest, why would it be like right here, right

David:

[

I know, Brenda, I thought, that's

why I thought like 'cause at that very point, no ((shifts position in chair to sideways and emphasizes "point" by striking finger on table) $=$

133 Brenda: Why wouldn't it be right before that center point?

134

135 David:<smiles>[AlH2]</smiles>

what you mean ((shrugs one shoulder))

136 Brenda: Thank you! ((laughter from several in class))

137 David: If that question was on a test, I'd a probably got it wrong because (unclear)

Although David appears to share a conceptual dilemma similar to Brenda's, he has remained almost completely silent throughout the entire discussion. Rather than engaging socially to resolve the difficulty, David seems to have resigned his inability to solve the problem as a settled matter of institutional stability - a mystery that 
would have passed by him on a test. Brenda's response to David reflects the social isolation she is sensing and her affective instability because of it; she is genuinely relieved and thankful that someone else expresses a struggle.

Charlene, who is unable to respond to Brenda's challenge and David's agreement with it, turns back to the board and indicates the teacher's mathematical formulas, bringing this discursive code back into play:

138 Charlene: But if you just look at the formula ((points back to board with right arm while shoulders remain mostly squared to Brenda)) like that thing up there then that makes more sense ((pulling arm back in)).

Charlene's remark and body position may well be the richest moment in the entire transcript. The formula, as just a "thing up there," cannot make sense of Charlene's explanation of maximizing velocity. Rather, it is an authoritative, mathematical discursive code that is literally and figuratively backing her evidence up. Rather than being embedded within the evidence she presents, it is a direction to point and work toward. Thus, Charlene's way of working supports the teacher's institutional stability, located in "vibrating around" a given solution until one arrives at it. Furthermore, Charlene's body position and gestures at this point are fascinating. She is seated across from Brenda in her effort to help her, and when her explanation fails, she points back with one arm toward the formula while still maintaining her shoulders squared to Brenda. In this manner, she builds a bodily bridge between her own internally persuasive discourse and the authoritative discourse of the teacher, between an idea of maximizing acceleration within an interval and the teacher's equations. This bridge is also social: As a close friend of Brenda's, she works to align her with the rest of the class. When Brenda continues to disagree and counter, destabilizing Charlene's weak conceptual and social position, Charlene's response is a telling critique of how one ought to proceed in the science classroom:

140 Brenda: I know- but- I don't understand physically ((strikes hands together a few times with back of one hand to palm of other)) how it would work, because if it's gotta go from zero ((points up with right hand, draws small circle in space with pencil in hand, then points ahead with left hand)) to the maximum velocity, from here to here ((indicates point up with right hand and swings this hand down to the left hand; at "if it's gotta go," Charlene gets up and walks back toward her seat at the front of the room)).

141 Charlene: ((looks back while walking away)) How are we supposed to explain it to you in your own words? You like understand but you don't understand. 
142 Teacher: Okay, let's imagine you

143 [

144 Brenda: Yeah, but I don't understand it

145 Charlene: You understand, but you don't believe it.

146 Brenda: I don't understand it

147 Teacher: Brenda, Brenda! ((smiling))

148 Brenda: Yes?

149 Teacher: Imagine a baby with his or her mother=

Charlene takes Brenda to task for not "believing," that is, for not taking the formula-based proof on face value and proceeding from there. She appears to suggest that Brenda can understand the proof as a means of mathematics - that all she needs to do is "believe" that it holds and not insist on her "own words." Such a view would support the teacher's stated process of how the students ought to proceed as well as the institutional goals of moving through a test review. At the same time, in affirming that Brenda (already) "understands," and that her disbelief is an institutional preference rather than a conceptual problem, Charlene may be affirming her social support for Brenda as a thinking person. However, Brenda's sense of understanding is to align the situation and solution as given information with her current understandings of concepts such as acceleration; she says she is "trying to make it so [she] understand[s] both" (turn 167) what the teacher critiques as her "own intuitive thinking" and "the systematic thinking, in science" (turn 165).

When Charlene's closes down her efforts to mediate, the teacher takes up a strategy that he introduced and that Michael and Charlene followed after him-introducing yet another illustration as proof. In this case, the teacher not only radically alters the focal stability, shifting to a story of a mother in a grocery store controlling a baby by an elastic tether but also shifts his own discursive code. The story he creates, with its drama, gesturing, and personification of forces, suggests a high degree of response to Michael's narratives as well as introduces another set of conceptual instabilities.

\section{DISCUSSION}

Our three opening questions in this article frame our discussion. First, how does the multilayered framework of (in)stabilities help us to interpret the historical and ongoing construction of this context? Although we have already addressed this question through both overview and microanalysis, here we consider in particular the coordination of the teacher's mathematical-authoritative discourse with the current institutional agendas. Second, how are participant positions negotiated within this context? Turning our focus to the students, we describe how their positions within the class might be better understood as multilayered responses to their so- 
cially constructed locations within the discussion. Third, we attempt to address the thorny problem of conceptual change, in its fully situated sense, and posit why it is that Brenda, despite all of the intervention made on her behalf, never understands the solution to the problem.

\section{Constructing the Context}

The analysis of this dance of (in)stabilities describes ways in which the participants in the classroom continually construct a collective activity system. Significant in any activity system is the subject-object relation, the goal-directedness of the system as a mode of production. In the activity system at hand, we argued that the institutional goals of performing a test review and moving through problems, which at times involves simply "buying" scientific ideas rather than understanding them, is highly coordinated and supported by the teacher's authoritative discourse. This authoritative discourse itself is characterized by fixed mathematical equations. Whether or not the students believe or understand the equations, the teacher's goal is that they begin and end with them; if doubts or problems arise, they are to find their own way back to the equations.

Although critics have frequently characterized school science as having fixed end points and predetermined paths, the case here suggests ways in which the process of stabilization of goals and activity is carried out. In the teacher's activity, the use of mathematical equations is a highly efficient means of summarizing a scientific idea and its history. The mathematical discourse can be described as a formal necessity, a mediation within the classroom of broad activities and histories of science. At the same time, the close alignment of such discourse with institutional stability raises questions about the extent to which formal mathematical discourse may serve not only scientific goals but also institutional goals. Here, the discourse stabilizes the divergent histories and activities of students learning science in order to move them through the activity of a test review. The mathematical tool is also an institutional tool; if the students will just take the equations into the test, they will reach institutional goals. David remarks that, before the discussion, he would have "got [the problem] wrong" on a test and suggests that now he knows the answer, even though he does not understand it.

\section{Locating Oneself In and Through the Dance}

Despite the strong alignment of institutional goals and authoritative, mathematical discourse on the teacher's part, and despite the teacher's ultimate closure of the event and dominant presence even in more "open" discussion, it is important to consider the many more subtle and hidden ways in which students coordinate their actions 
with the teacher's discourse, goals, and institutional stability. The ongoing construction of the activity system is characterized by negotiations, struggle, and inner contradictions (Engestrom, 1993). Significantly, none of the students who participate in the conversation proceed by simply taking up the teacher's discourse, by fully adopting and expressing its mathematical-authoritative form. In fact, this discourse type is most conspicuous by its absence in the students' interactions. Even Michael, who is highly aligned with the teacher (as exemplified in their coconstructions of the focal problem) puts the teacher's mathematical discursive authority to little use. Rather, Michael constructs his understanding primarily through animated narratives, which includes embodying the problem construction in lively gesturing. When Michael does make slight moves to the authoritative discourse of the teacher, he is censured by the class, and he suggests other possibilities to the problem, a conceptual nod to doubt, thereby relocating himself as a typical student, who does not "necessarily even have a clue" (turn 114). Michael's case suggests the degree to which students' desires to understand and express understanding cannot be separated from how they understand one another's positions in the classroom. Too much understanding of esoteric science, and especially the use of uncommon terms and equations, may construct a student as being too heavily aligned with the teacher, too unlike other students. Michael's case suggests that, even if a student were to fully understand the authoritative equations and terms, there may well be social reasons not to make use of them. The discourse that students take up in solving problems should not be merely judged on the basis of their relation to the problem situation and teacher talk itself but on an understanding of their historical locations and active constructions of their own subjectivities within the activity system.

From a Bakhtinian (1981) standpoint, what is most intriguing are the points of contact - the hybrids - in which individual language consciousness come together and form a mixture. In this context, we can interpret what Bakhtin calls the centripetal forces of language practices (a pulling toward authoritative normalization) and the centrifugal forces (an opposing pull toward diversity, change, and individuality) within the creation of the hybrid positions that are formed. Michael's hybrid stance is that he has found his own means to construct an understanding of the problem through narrative, and he is able to bring bits of authoritative discourse to it. Charlene's hybrid discourse is even more intriguing. Charlene patched together a focal and conceptual view based on "maximizing acceleration" over an interval that does not correspond to the mathematical-authoritative discourse. However, Charlene points to the equations represented on the board as a "thing up there" that allows her a solution that "makes more sense" (turn 138). Significantly, although Charlene's internally persuasive discourse (her conceptual construction) is at odds with the mathematical-authoritative, she uses them to support one another. She has found a way to believe the equations, and conversely, the equations entitle any explanation that agrees with them a certain degree of authority. When this hybrid position is challenged, in fact, split down the middle by Brenda (with the help of 
David), Charlene turns to another resource of stability within the movement of the classroom: institutional stability. Charlene's divided participant position at this moment is reflected in the double orientation of her body as well as in her discourse. Even though Charlene is unable to align with the teacher's mathematical-authoritative discourse, she assists in moving Brenda and the class toward institutional stability by critiquing Brenda for not "believing" the solution.

Conceptually, David and Brenda appear to be struggling with the same aspect of the problem - how "at that very point" of no motion the oscillator can be at a point of highest acceleration. At the same time, socially and institutionally, their approaches to the problem are sharply contrasting and worth considering. David primarily chooses to ignore his doubts and not pursue them; it is only after the constant challenging by Brenda that he joins in the fray and then only briefly. David appears to have displaced most of his conceptual struggle for institutional goals. His closing remark suggests that now that he knows the answer he could get the problem right on a test but that an internalized understanding of the problem may never come. Brenda, on the other hand, exemplifies the most extreme example of a student posing an internally persuasive, yet unstable, position in opposition to the authoritative discourse. Brenda's refusal to "buy" the given authoritative response and her desire to connect her own reasoning with the teacher's discourse locates her at odds with the teacher's agenda and the institutional movement of the class. Even with respect to her peers, there is an increasingly narrowed space for Brenda's activity within this system. She concedes that "it's obvious the point's right" (turn 119) at a moment of highest social instability, when every student still speaking has either found a way to make the correct answer make sense or has simply decided to accept it and move on (e.g., David).

These cases suggest the ways in which the students coordinate their discourse and actions with respect to one another, the teacher's mathematical-authoritative discourse, and the (institutional) purposes of carrying out a test review. They illustrate how the construction of the context and authority is not entirely fixed by the teacher but by all the participants within the activity system. Furthermore, the system construction and its institutional goals begin to suggest how and why Brenda's position of dissent, based on wanting to come to conceptual understanding, is increasingly closed down. However, we need to consider further the particular types of interventions that are made on Brenda's behalf because a good deal of effort goes into convincing her and moving her along with the class. In brief, why is it, despite all of the activity and discourse used to mediate her thinking, that Brenda does not come to an understanding?

\section{Understanding Brenda's Failure to Understand}

Based on any of the dynamics discussed previously, it is hard to imagine this discussion as a successful experience for Brenda. Socially and affectively, she has be- 
come increasingly isolated and frustrated. Institutionally, she has held up the progress of the test review; conceptually, her understanding has not changed. On the other hand, there is a good deal going on in the discussion that might be otherwise regarded as positive: Students are given a large amount of time to "talk science," this talk links to real-world experience, and there is a great deal of engagement by a number of students. In such an environment, one might expect some conceptual change or at least more evident signs of conceptual instability on Brenda's part. On the contrary, Brenda's conceptual understanding is highly stable; in fact, in a classroom interaction several days after this extended discussion, she expressed a belief about acceleration consistent with her arguments here.

Brenda's stable conceptual view may be approached from many of the different dynamics we have outlined earlier. Institutionally speaking, one could readily make an argument that the context constructed here does not allow space for Brenda to understand - that Brenda's goal to understand does not match the institutional agenda coconstructed by the teacher and other students of moving through a test review. Socially and affectively speaking, we argued that Brenda is increasingly closed out of the circle of interaction. Yet, despite the teacher's closure of the discussion for institutional goals, it is not clear that continuing the same type of discussion would assist Brenda. Despite negative social and affective movements, Brenda actively resists these social and institutional pressures and still seems willing to pursue understanding even as the teacher prematurely shuts the discussion down. Although institutional, social, and affective barriers clearly hinder Brenda's efforts, none of them appear to be entirely sufficient reasons for her conceptual stability.

We would argue that two related failures to connect or bridge instabilities offer robust explanations for Brenda's failure to be conceptually more unstable or come to an understanding. First, the discussion on the whole fails to build substantial connections between focal and conceptual instabilities. One could argue that Michael's introduction of the vertical spring is stabilizing, lending some coherence to two situations that were previously disparate (the horizontal oscillator and the falling pencil). This intermediate function seems to be Michael's intent because his "Here, OK" comes right after the teacher's expressed frustration at Brenda's lack of assent. Furthermore, right before this point, Brenda and the teacher had tussled over the issue of acceleration at the top of the toss, leading to the teacher's "In this case we have a spring" (turn 96). In contrast to this effort by Michael, the teacher's focal introductions (simple harmonic oscillator, tossing a pencil, and mother with baby) seemed to come from an attempt to stabilize authoritatively by providing examples from an abstract, authoritative principle. In a similar vein, Brown (1992) found that examples of an abstract principle were much less helpful for students than were "bridging analogies" that attempted to bridge focal and conceptual stability among a set of anologically related situations.

Brenda has trouble appropriating the vertical spring situation, but her conceptual assimilation of the situation is arguably substantially different than Michael's. 
Michael is focusing on the change in the object's velocity, whereas Brenda appears to be focusing on the object's agency or "umph," which she calls acceleration. Still, she easily discusses the situation with Michael, effortlessly appropriating the particulars of the situation while conceptually focusing very differently. This not only indicates substantial intrapersonal conceptual stability for both Michael and Brenda, but also substantial, tacit, conceptual interpersonal instability.

Brown (1992) discussed three factors that emerged as important in a tutoring study comparing an explanation involving examples of an authoritative principle (Newton's third law) and an explanation involving explicit development of analogical relations among several situations. These three factors were as follows: (a) Situations must make sense to students, (b) there is a need to explicitly develop analogy relations (versus simply relating each situation to the same abstract principle), and (c) the analogy relations should help students develop new explanatory models. Michael attempts to accomplish the second factor for Brenda (although he does not make explicit connections to other situations), but this is not rooted in a shared understanding of at least one of the situations (the first factor) and, as such, does not help Brenda refocus with a new explanatory model (the third factor). The teacher attempts to fulfill the first factor with his mother and baby analogy but ties it to an abstract principle rather than relating it to other situations ("The acceleration of the baby, is equal to the force of the rubber band, divided by the mass of the baby"). The analogy fails to help Brenda refocus conceptually.

We have discussed these particular examples as failures to bridge between the focal and conceptual because we believe that they are suggestive of how the discussion proceeds on the whole - the heaping of one situation on another, with weak and primarily tacit connections to abstract principles. This process may even assist Brenda in stabilizing her views on acceleration because she is able to readily assimilate the different proofs to her own conceptual view.

Also conspicuously absent in the discussion is any bridge between the teacher's mathematical-authoritative discourse code and the internally persuasive means through which the students construct their understandings. Brenda's statement that she is "trying to ... understand both" (turn 167) the "systematic thinking" in science and her own intuitive thinking is perhaps the clearest statement of the failure of the discussion to construct possible bridges or to make explicit what is operating within these different forms of discourse. It is only very late in the discussion, in his frustration, that the teacher makes explicit how he expects students to proceed. Although "systematic" thinking is urged throughout, ideas about this form of thinking remain tacit. None of the students make extensive use of the mathematical-authoritative discourse to construct their understandings. Furthermore, the teacher, when making forays into the discursive types students appear to favor (e.g., narrative), soon returns to the mathematical-authoritative discourse. In short, Brenda's efforts of "trying to ... understand both" - of trying to negotiate the discursive field between the authoritative and internally persuasive-is not 
modeled in the class, and the general discursive instability itself is not made explicit. Rather, failure to bridge between discursive-symbolic codes is constructed as conceptual failure or as institutional resistance by the other interactants.

\section{CONCLUSIONS}

In this article, we addressed the limitations of classroom discourse analysis that separates a focused and desirable signal from an undesirable and divergent noise. In attempting to carefully foreground the diverse types of signals that are always at work in classrooms as well as their coarticulation, we developed a multilayered framework. The dynamics that emerged from this analysis are characterized as (in)stabilities. This term, unstable in its own right, captures something for us of both the activity-like and structure-like nature of dynamics within the interaction. As unfolding interactions, we might feature the range of unstable negotiations and movements in constructing the context at hand. As structures, we might characterize where any aspect of the system becomes sedimented or concretized, that is, where the context is overly determined for a particular type of activity. The term (in)stability, a hybrid of interaction and structure, is a means of analyzing both fixation and flow, and it allows us to examine how instabilities interrupt more stable moments of interaction and how an array of unstable forms might coordinate with relatively stable forms and goals.

\section{Implications for Research}

The (in)stabilities we identified and used in our framework - conceptual, focal, discursive-symbolic, institutional, social, and affective-were analyzed for the ways in which they coordinate and contrast with one another in the flow of interaction. At a broad level of analysis, the (in)stabilities suggest functional pairs: Focal and conceptual, discursive-symbolic and institutional, and social and affective (in)stabilities appear to be highly coordinated. Particularly mapped out in this analysis is the predominance of an institutional stability - carrying out a test review - and how it is performed by way of the teacher's mathematical-authoritative code. We argued that this discursive form is illustrative of Bakhtin's (1981) "authoritative discourse," in that students seem to have little means of shaping responses to it. However, the institutional agenda is also supported by students through alternate discursive-symbolic codes and means, including how they lend social, affective, and focal support to the teacher's efforts. This is just one example in which various forms of stability or instability converge and coconstruct either consensus or dissent. Thus, at a microlevel, the interactions are highly flexible and often indeterminate with respect to the resources they draw on; the teacher and students alike make use of different resources within the interaction to achieve their goals. 
Further research using this developing framework and other multidimensional approaches could help us better understand the use of particular discursive codes and practices that are closely aligned with institutional purposes. In addition, such frameworks have promise in the service of understanding students' participant positions with respect to classroom discourse practices. Our study illustrates that students' positions in the classroom within the course of interaction can be best understood through multiple lenses. At a minimum, the analysis argues against making assumptions that student responses to what we consider to be conceptual questions are themselves conceptually motivated. Rather, student responses may well be located at the intersection of social, affective, institutional, and other meanings. The analysis and framework offers a means of understanding how students are not simply responding with answers to problems but are shaping their own positions as participants within the flow of interaction.

Furthermore, in working out their positions, students both actively construct and resist institutional agendas of schooling, including rapid coverage of material and acceptance of fuzzy beliefs rather than understandings. The study has developed four portraits of student positions by analyzing their internally persuasive responses to the physics problem and their activity within the discussion. The 4 students illustrate a range of responses that we believe to be prototypical of students in many other science classroom contexts. Michael's response, the most hopeful of the four responses from a learning perspective, is to form his own animated story of the scientific situation, which serves him as a preliminary bridge toward the mathematical proof offered by the teacher. Michael borrows from, but is uncomfortable with, elements of the teacher's authoritative language. Charlene, like Michael, constructs her own account, but in her case, the story widely diverges from the formal scientific proof, and Charlene's understanding is effectively (and, within the interaction, socially) split between the mathematical account and her personal understanding. David has seemingly given up on an internally persuasive means of understanding and accepts the formal scientific proof, along with its institutional agenda, as the only means of proceeding. Brenda appears to have the same conceptual difficulty with the problem as David; yet, she continually resists any explanation that cannot bridge between formal scientific and authoritative discourse and intuitive, or internally persuasive, discourses. Clearly, further research is needed to better understand students' positions of resistance and cooperation in science classrooms, especially what such positions mean with respect to science learning. Considering such positioning and repositioning through a multilayered framework could prove highly productive.

\section{Implications for Instruction}

Within the ongoing dance of (in)stabilities, we argued that two instructional failures are largely responsible for Brenda's inability to make meaning of the scientific 
response to the problem, that is, for her ongoing conceptual stability. First, although many different situations are presented in an effort to convince Brenda, there is a conspicuous lack of bridging between these situations and various conceptual viewpoints. Even though the shifting situations are often recognized and even appropriated by interactants with radically differing conceptual views, conceptual (in)stabilities remain tacit and unexplored as interpretive frameworks for situations. Similarly, the differences in discursive-symbolic codes remain tacit; connections between the teacher's mathematical-authoritative discourse and the students' discursive forms are not formed. Although the students, and less so the teacher, attempt to construct bridges between divergent ways of speaking, proving, and thinking, the nature of these bridges (or even their pressing need) remains hidden. Hopes of avoiding such "speaking past" rather than "speaking with" appeal, once again, to the need to make visible for our students and ourselves not only what it is that we are doing in science classroom interactions but how - and why.

Speaking more broadly, we hope that the multiple lenses offered through this framework prove valuable to teachers in planning and reflecting on classroom interactions and even negotiating with them in real time. The six domains of (in)stability and their dynamic relations offer a broad tool with which teachers can reflect on specific responses and common discourse practices, a means of understanding how problem posing and problem solving in classrooms involves much more than the construction of concepts. Furthermore, the framework prompts us to ask, as teachers, how and where we want our center of stability to be in the classroom and how such goals align with our current practices.

\section{ACKNOWLEDGMENTS}

Kevin M. Leander thanks the Spencer Foundation and the National Science Foundation for their support during the production of this article. In addition, both of us are grateful to the anonymous reviewers for their thoughtful response to an earlier version of this article.

\section{REFERENCES}

Bakhtin, M. M. (1981). The dialogic imagination: Four essays by M. M. Bakhtin (M. Holquist, Ed., and C. Emerson \& M. Holquist, Trans.). Austin: University of Texas Press.

Bakhtin, M. M. (1986). Speech genres and other late essays. (C. Emerson \& M. Holquist, Eds., and V. W. McGee, Trans.). Austin: University of Texas Press.

Brown, D. E. (1992). Using examples and analogies to remediate misconceptions in physics: Factors influencing conceptual change. Journal of Research in Science Teaching, 29, 17-34.

Brown, D. E. (1993). Refocusing core intuitions: A concretizing role for analogy in conceptual change. Journal of Research in Science Teaching, 30, 1273-1290. 
Brown, D. E. (1995, April). Theories in pieces? The nature of students' conceptions and current issues in science education. Paper presented at the annual meeting of the National Association for Research in Science Teaching, San Francisco.

Cazden, C. B. (1988). Classroom discourse: The language of teaching and learning. Portsmouth, NH: Heinemann.

diSessa, A. A. (1988). Knowledge in pieces. In G. Forman \& P. Pufall (Eds.), Constructivism in the computer age. (pp. 49-70). Hillsdale, NJ: Lawrence Erlbaum Associates, Inc.

diSessa, A. A. (1993). Toward an epistemology of physics. Cognition and Instruction, 10, 105-225.

Driver, R., Asoko, H., Leach, J., Mortimer, E., \& Scott, P. (1994). Constructing scientific knowledge in the classroom. Educational Researcher, 23(7), 5-12.

Dore, J., \& McDermott, R. P. (1982). Linguistic indeterminacy and social context in utterance interpretation. Language, 58, 374-398.

Duckworth, E. (1987). "The having of wonderful ideas” and other essays on teaching and learning. New York: Teachers College Press.

Edwards, D., \& Mercer, N. (1987). Common knowledge: The development of understanding in the classroom. New York: Routledge.

Engestrom, Y. (1993). Developmental studies of work as a testbench of activity theory: The case of primary care medical practice. In S. Chaiklin \& J. Lave (Eds.), Understanding practice (pp. 64-103). Cambridge, England: Cambridge University Press.

Goffman, E. (1981). Footing. In Forms of talk (pp. 124-159). Philadelphia: University of Pennsylvania Press.

Gutierrez, K., Rymes, B., \& Larson, J. (1995). Script, counterscript, and underlife: James Brown versus Brown vs. Board of Education. Harvard Educational Review 65, 445-471.

Hammer, D. (1996). Misconceptions or p-prims: How might alternative perspectives of cognitive structure influence instructional perceptions and intentions? The Journal of the Learning Sciences, 5 , 97-127.

Lave, J. (1988). Cognition in practice: Mind, mathematics and culture in everyday life. Cambridge, England: Cambridge University Press.

Lemke, J. L. (1990). Talking science: Language, learning, and values. Norwood, NJ: Ablex.

Leont'ev, A. (1978). Activity, consciousness, and personality. Englewood Cliffs, NJ: Prentice-Hall.

McCloskey, M. (1983). Naive theories of motion. In D. Gentner \& A. L. Stevens (Eds.), Mental models (pp. 299-324). Hillsdale, NJ: Lawrence Erlbaum Associates, Inc.

McDermott, R. P., \& Roth, D. (1978). The social organization of behavior: Interactional approaches. Annual Review of Anthropology, 7, 321-345.

Pfundt, H., \& Duit, R. (1998). Bibliography: Students' alternative frameworks and science education (5th ed.). Kiel, Germany: Institut für die Pädagogik der Naturwissenshaften.

Piaget, J. (1977). Problems of equilibration. In H. E. Gruber \& J. J. Voneche (Eds.), The essential Piaget: An interpretive reference and guide. New York: Basic Books.

Pontecorvo, C., \& Girardet, H. (1993). Arguing and reasoning in understanding historical topics. Cognition and Instruction, 11, 365-395.

Prior, P. (1995). Tracing authoritative and internally persuasive discourses: A case study of response, revision, and disciplinary enculturation. Research in the Teaching of English, 29, 288-325.

Resnick, L. B., Salmon, M., Zeitz, C. M., Wathen, S. H., \& Holowchak, M. (1993). Reasoning in conversation. Cognition and Instruction, 11, 347-364.

Rommetveit, R. (1992). Outlines of a dialogically based social-cognitive approach to human cognition and communication. In A. Wold (Ed.), The dialogical alternative: Towards a theory of language and mind (pp. 19-44). Oslo, Norway: Scandinavian University Press.

Voloshinov, V. N. (1973). Marxism and the philosophy of language (L. Matejka \& I. R. Titunik, Trans.). New York: Seminar Press. (Original work published 1929). 
Vosniadou, S., \& Brewer, W. F. (1992). Mental models of the earth: A study of conceptual change in childhood. Cognitive Psychology, 24, 535-585.

Wertsch, J. (Ed.). (1981). The concept of activity in Soviet psychology. New York: Sharpe.

Yates, J., Bessman, M., Dunne, M., Jertson, D., Sly, K., \& Wendelboe, B. (1988). Are conceptions of motion based on a naive theory or on prototypes? Cognition, 29, 251-275. 